\title{
ÁRON KISS UNGARISCHE GESELLSCHAFT FÜR SPIEL- UND SPIELZEUGFORSCHUNG (A KISS ÁRON MAGYAR JÁTÉK TÁRSASÁG)
}

\author{
Erzsébet GYÖRGYI
}

H-1024 Budapest, Buday László u. 7. Ungarn

Die Ungarische Gesellschaft für Spiel- und Spielzeugforschung - namens Áron Kiss - wurde 1987 in Kecskemét gegründet. Ein Jahr zuvor wurde im Spielzeugmuseum Szórakaténusz ein Symposium über das Spiel veranstaltet, bei dem der Vorschlag zur Gründung der Gesellschaft gemacht wurde. Gründer der Gesellschaft waren Museologen, Volkskundeforscher und Kulturhistoriker, Pädagogen, Techniker, Spielzeugsammler, Volkskünstler und Spielzeughersteller. Die Zielsetzung der neuen Gesellschaft war die Förderung der vernachlässigten ungarischen Spielkultur. In der Nachkriegszeit waren die traditonellen Gemeinschaften im Land aufgelöst worden, wodurch sich die Spielmöglichkeiten für Kinder und Jugendliche verringert hatten. Für die verlorenen Möglichkeiten gab es nicht genügend zeitgemäße neue, und auch die Spielwarenproduktion war nicht auf dem höchsten Stand. Die neue Gesellschaft gab die Möglichkeit, enge Verbindungen zwischen den verschiedenen, voneinander isoliert tätigen Arbeitsfeldern auszubauen.

Der Namengeber Âron Kiss (1845-1908) war Professor, Schuldirektor und ein großer Pädagoge seiner Zeit, und er war der Sammler und Herausgeber der ersten ungarischen Spielzeugsammlung Magyar Gyermekjátékgyújtemény, die 1891 in Budapest erschien. Diese reiche Sammlung ermöglichte, daß ungarische Kinder im Kindergarten traditionelle ungarische Kinderspiele erlernen konnten.

Der erste Präsident der Gesellschaft - der sich zusammen mit dem ersten Sekretär der Gesellschaft, Dr. József Kriston Vizi, dem Direktor des Spielzeugmuseums Szórakaténusz in Kecskemét, am meisten für die Gründung der Gesellschaft einsetzte - war Tibor Szentiványi, Elektroingenieur und Spielzeugsammler bzw. -experte. Seit 1982 war er - und ist er bis heute - der Leiter eines Spielklubs namens MELEDA, eines Selbstbildungskreises für erwachsene Spieler. Die Gesellschaft wurde von ihnen beiden bis 1996 geleitet - unterstützt durch das Präsidium. Es wurden vier Fachsektionen geschaffen: 1. Sektion für Spielzeug- und Spielgeschichte, 2. Spiele im Dienste der Pädagogik und Heilpädagogik, 3. Spiele unseres Zeitalters - moderne Spiele und 4. Entwicklung, Herstellung und Verbreitung von Spielen und Spielgeräten. Am aktivsten war die Volkskundliche Arbeitskommission, die ihre Tätigkeit im Rahmen der ersten Sektion ausübte. 1989 wurde eine ganztägige Sitzung dieser Kommission zusammen mit dem Institut für Volkskunde der Akademie der Wissenschaften veranstaltet. Die Spielpädagogische Sektion betätigte sich in Zusam- 


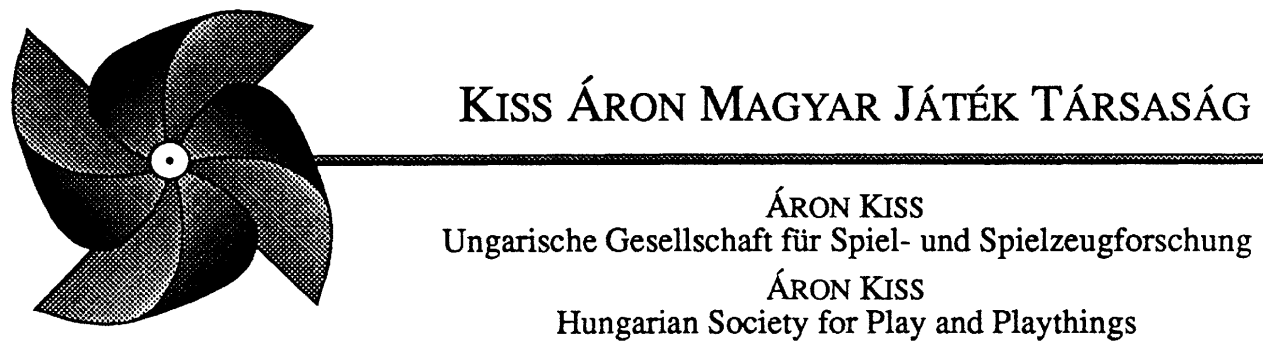

menarbeit mit der pädagogischen Hochschule in Hajdúböszörmény, wo sie jährlich oder je zwei Jahre am Spielpädagogischen Forum mitarbeitete. Mehrere Sitzungen wurden von der Gesellschaft veranstaltet, die hervorragendste fand am 14. Mai 1993 über „Die Situation der Spielkultur in Ungarn“ in der Pädagogischen Hochschule in Buda statt. Wichtige Themengruppen, die diskutiert wurden, waren Spielpädagogik, Spielgewohnheiten, Bewahrung der Tradition, Spiele unserer Zeit, Spielsoziologie, Spielwarenproduktion und -handel, Spiel in der Literatur sowie Sport und Spiel 1993 war die Gesellschaft Mitveranstalter einer gemeinsamen Sitzung mit tschechischen und slowakischen Spielzeug- und Spielfachleuten. Es wurden in Zusammenarbeit mit anderen Institutionen mehrere Wettbewerbe für Spielprojekte ausgeschrieben, die großes Interesse weckten und viel Erfolg brachten. 1992 wurde der Gesellschaft vom Minister für Jugend für mehrjährige erfolgreiche Tätigkeit im Bereich der Spielkultur Imre-Szacsvay-Preis verliehen.

Die Gesellschaft gibt seit ihrer Gründung das zuerst vervielfältigte, später gedruckte Informationsblatt Tájékoztató heraus. Außer Nachrichten aus dem Leben der Gesellschaft enthält es Auskünfte über Neuerscheinungen, Ausstellungen, Treffmöglichkeiten und andere Neuigkeiten.

Es wurden enge Beziehungen mit dem Geburtsort von Áron Kiss, der Gemeinde Porcsalma ausgebaut. In der Schule wurde eine Gedenktafel eingeweiht, und im Dorf steht die Statue des Namengebers.

Selbstverständlich wurde die Zusammenarbeit mit verschiedenen Institutionen im Interesse der Tätigkeit für das Spiel ausgebaut. Auch internationale Verbindungen wurden gefördert. Die Nürnberger Spielzeugmesse (und damit das Museum Lydia Bayer) wurde von unserer Gruppe mehrmals besucht. Mit ausländischen Vereinigungen wie dem International Council for Play and Playthings (Groningen), der International Association for Child's Right to Play (Stockholm) und der Toy Library Association (Dänemark) wurden Kontakte aufgenommen. Mehrere anerkannte Spielfachleute aus verschiedenen Ländern Europas besuchten die Gesellschaft.

1996 wurde ein neues Präsidium gewählt. Die Gesellschaft ist von Kecskemét nach Budapest umgezogen. Das Museum des Stadtteils Óbuda (Altofen) hat Räume und technische Hilfe zur Verfügung gestellt, hier ist die Adresse der Gesellschaft: $\mathrm{H}$ 1033 Budapest Fó tér 1. Óbudai Múzeum. Tel./Fax: (36-1) 250-10-20. Dieses Museum besitzt und stellt ständig eine reiche Spielzeugsammlung aus. Die Hauptstadt 
Budapest hat kein eigenes Spielzeugmuseum. Im Rahmen dieses kleinen Museums besteht die Möglichkeit, ein Budapester Spielzeugmuseum langsam aufzubauen. Unsere Gesellschaft leistet dazu fachliche Hilfe.

In letzter Zeit veröffentlichen die Mitglieder neben dem Informationsblatt - das durchschnittlich jährlich erschien - auch Briefe, kürzere Mitteilungen, die aktueller informieren können. Das Puppenprofil der Gesellschaft wurde kräftig verstärkt: ein Puppenklub wurde gegründet, und im Jahre 1998 arbeiteten wir zum zweitenmal an der Mitteleuropäischen Puppenkonferenz mit, die Ende September in Győr veranstaltet wurde.

In zwei Regionen, in den Komitaten Szabolcs-Szatmár-Bereg und Győr-MosonSopron wurden 1998 Komitatsabteilungen unserer Gesellschaft gegründet. Diese Art von Organisation ermöglicht es den Spielfreunden, sich an Ort und Stelle zu treffen, ohne die Hauptstadt zu besuchen.

Eine neuere Bestrebung der Gesellschaft ist es, die Methode der gemeinsamen Kinderspieltätigkeiten zu vervollkommnen und zu verfeinern. Junge Kolleginnen (Emese Joó, Piroska Nagy) arbeiten daran, die ganze Familie in Spielprogramme einzubeziehen.

Es dürfen auch die „Steckenpferde“ („Vesszőparipáink“) nicht vergessen werden, die kleinen, aber wertvollen Hefte der Gesellschaft. Das erste befaßt sich mit der Persönlichkeit von Áron Kiss, ${ }^{1}$ das zweite mit der Geschichte der Spielpädagogik in Ungarn, ${ }^{2}$ und das dritte hat einen bunten ethnographisch-kulturhistorischen Inhalt. ${ }^{3}$

Die Mitgliederzahl der Gesellschaft wächst, und die zehnjährige Tätigkeit hat ihre Spuren hinterlassen. In den Schulen achtet man neben dem Lernen mehr auf das Spiel. Wir sind bestrebt, unsere Tätigkeit zu erweitern und Verbindungen auszubauen, und suchen dabei auch Kontakte mit Museen, Instituten und Spielfreudigen.

\footnotetext{
${ }^{1}$ KRISTON VízI, József (Hrsg.): Kiss Áron Emlékezte (Erinnerung an Áron Kiss). Kecskemét-Budapest 1990, p. 41. Vesszőparipáink. A Magyar Játék Társaság Közleményei 1.

2 W. MıKó, Magdolna (Hrsg.): A múlt század kiemelkedő játékpedagógiai eredményei (Die herausragenden spielpädagogischen Ergebnisse im vergangenen Jahrhundert. Budapest 1992 p. 111. Vesszőparipáink. A Magyar Játék Társaság Közleményei 2.

${ }^{3}$ KRISTON VÍZI, József (Hrsg.): Játék + Rend + Szerek (A facsigától a játékprogramig) (Spiel + Ordnung + Mittel - Vom Holzkreisel bis zum Spielprogramm.) Kecskemét-Budapest 1996. Vesszőparipáink. A Magyar Játék Társaság Közleményei 3.
} 